University of New Hampshire

University of New Hampshire Scholars' Repository

$11-1-2002$

\title{
Enhancement of wind-driven upwelling and downwelling by alongshore bathymetric variability
}

James M. Pringle

University of New Hampshire, James.Pringle@unh.edu

Follow this and additional works at: https://scholars.unh.edu/earthsci_facpub

Part of the Earth Sciences Commons

\section{Recommended Citation}

Pringle, James M., "Enhancement of wind-driven upwelling and downwelling by alongshore bathymetric variability" (2002). Journal of Physical Oceanography. 11.

https://scholars.unh.edu/earthsci_facpub/11

This Article is brought to you for free and open access by the Earth Sciences at University of New Hampshire Scholars' Repository. It has been accepted for inclusion in Earth Sciences Scholarship by an authorized administrator of University of New Hampshire Scholars' Repository. For more information, please contact Scholarly.Communication@unh.edu. 


\title{
Enhancement of Wind-Driven Upwelling and Downwelling by Alongshore Bathymetric Variability*
}

\author{
JAMES M. PRINGLE \\ University of New Hampshire, Durham, New Hampshire
}

(Manuscript received 13 April 2001, in final form 17 April 2002)

ABSTRACT

\begin{abstract}
Steady wind-driven flow along a shelf of changing width is described with a frictional barotropic model valid in the limit of small Rossby and Burger number. In these limits, an alongshore wind drives enhanced onshelf transport in a coastal ocean if the shelf widens downwind, and the change in shelf width only affects the flow in the direction of Kelvin wave propagation ("downwave") from the change in shelf width. There is enhanced onshore transport of cold, nutrient-laden bottom water if the winds favor upwelling and the shelf narrows in the direction of Kelvin wave propagation. This enhanced transport extends a considerable distance away from the change in shelf width but becomes concentrated near the shelf break far from the change in width. Isobath curvature on the scale of the shelf width significantly modifies local cross-shelf transport. The cross-shelf transport of nutrient-rich water during upwelling is expected to be enhanced from Point Eugenia to La Jolla, San Luis Obispo to Monterey, and Point Reyes to Cape Mendocino on the west coast of North America.
\end{abstract}

\section{Introduction}

If a wind blows along a shelf in the direction along which the shelf widens, more water will be forced onto the shelf from the deep ocean than if the shelf were of uniform width. Why this must be can be seen from the depth-averaged shallow-water alongshore-momentum equation in water of depth $H$ and in the limit of no alongshore variation:

$$
f \vec{u}^{0}=-g \ddot{\eta}_{y}^{0}+\frac{\tau_{\text {top }}^{y}}{H \rho_{0}}-\frac{r}{H} v
$$

where $u$, the depth-averaged cross-shelf velocity, is zero because of the coastal boundary condition and $\eta_{y}$, the alongshore surface pressure gradient, must be zero by the assumption of no alongshore variation. This leaves a balance between the bottom stress (here parameterized as a linear drag $r$ times the the depth-averaged alongshore velocity $v$ ) and the surface wind stress $\tau_{\text {top }}^{y}$. The alongshore velocity is then

\footnotetext{
* Global Ocean Ecosystems Dynamics Contribution Number 345 .
}

Corresponding author address: James Pringle, University of New Hampshire, 142 Morse Hall, 39 College Rd., Durham, NH 038243525.

E-mail: jpringle@cisunix.unh.edu

$$
v_{2 D}=\frac{\tau_{\text {top }}^{y}}{\rho_{0} r} .
$$

This velocity is everywhere uniform and downwind. Now consider a shelf that abruptly narrows. Consider two sections across the shelf far enough away from the change in shelf width that the flow through each section has adjusted to the new shelf width, has ceased to vary alongshore, and obeys (2). Since the velocity through the two sections will be the same, there must be greater transport through the wider section for its cross-sectional area is greater. Thus if the wind is blowing and the current flowing in the direction of a widening shelf, there must be a net transport of water from the deep waters onto the shelf to provide this additional transport.

This onshelf transport can be considerable. For a wind stress of $10^{-1} \mathrm{~Pa}$ (or about a $10 \mathrm{~m} \mathrm{~s}^{-1}$ wind) and a bottom drag coefficient of $r=5 \times 10^{-4} \mathrm{~m} \mathrm{~s}^{-1}$, (2) predicts an alongshore velocity of about $20 \mathrm{~cm} \mathrm{~s}^{-1}$ for regions well away from the change in shelf width. If a coastal ocean has a shelfbreak depth of $100 \mathrm{~m}$ and if the width of the shelf goes from 15 to $30 \mathrm{~km}$, the crosssectional area of the shelf will change by about $7.5 \times$ $10^{5} \mathrm{~m}^{2}$. This change in shelf width, multiplied by the alongshore velocity of $20 \mathrm{~cm} \mathrm{~s}^{-1}$, implies that $0.15 \mathrm{~Sv}$ $\left(\mathrm{Sv} \equiv 10^{6} \mathrm{~m}^{3} \mathrm{~s}^{-1}\right)$ of water must enter the shelf break in the vicinity of the change in shelf width. The importance of these cross-shelf flows at a given point on the shelf will be governed by the alongshelf distance 
over which the additional transport enters or leaves the shelf, and its importance to the biology and chemistry of the coastal ocean will be governed by the vertical distribution of the additional cross-shelf transport.

In order to discover where the flow is modified by the change in shelf width, it is necessary to create a simplified model of coastal wind driven flows. Careful analysis of the alongshore momentum balances in some wind-driven coastal oceans have found that the dominant balance was among wind stress, bottom drag, alongshore pressure gradients, and acceleration [Lentz and Winant (1986) near San Diego in winter, Lentz (1987) in the Coastal Ocean Dynamics Experiment (CODE) region in spring, Lee et al. (1989) in the South Atlantic Bight, and Lentz et al. (1999) and Lentz (2001) off North Carolina]. The simplest model that captures these dynamics is a linear homogeneous model with bottom friction. To further simplify the problem, time variation will be ignored, which is appropriate for timescales longer than the frictional spindown time of the shelf (Dever 1997). The papers above find that linear bottom drag coefficients from about $r=2 \times 10^{-4}$ to $5 \times 10^{-4}$ agree well with observations, which suggests a frictional spindown time $H / r$ of about 1-3 days in 50 m of water (cf. Dever 1997).

Because the model below is steady, homogeneous and frictional, it will not apply when the cross-shelf advection of buoyancy causes arrest in the bottom boundary layer, eliminating friction (e.g., Garrett et al. 1993 or Trowbridge and Lentz 1998) or when the alongshore buoyancy gradients are important in forcing cross- or alongshelf flows [Lentz and Trowbridge (2001) in the winter CODE region, Lentz and Winant (1986) in San Diego in summer, or Austin (1998) a frictional spindown time after the cessation of wind].

In the next two sections, a modified version of Csanady's (1978) arrested topographic wave equation is derived that includes the effects of a changing alongshore bathymetry, and the changes in upwelling and downwelling along a shelf of changing width are described. It will be argued that shelves that narrow in the direction of Kelvin wave propagation will be sites of enhanced onshelf transport near the bottom during upwelling, and thus enhanced onshelf fluxes of nutrients. A short comparison of the theory to some data will be made, and predictions of observable consequences of the theory will be given.

\section{Model equations}

The neglect of acceleration, nonlinearity, and stratification is only valid in several limits (see Hogg 1980). Janowitz and Pietrafesa (1982) show by a formal expansion in small parameters that stratification and the nonlinear advection of relative vorticity can be neglected relative to the advection of the planetary potential vorticity $f / H$ when

$$
\left(\frac{L_{D}}{L}\right)^{2} \leq \epsilon \ll \frac{\Delta H}{H}
$$

where $L_{D}$ is the internal radius of deformation, $L$ is the length scale of the alongshore variation of the bathymetry, $\Delta H$ the variation of the water depth that a streamline could encounter, $H$ is a scale water depth, and $\epsilon$ is the Rossby number $V(f L)^{-1}$. Here $V$ is a velocity scale for the geostrophic interior and $f$ is the Coriolis parameter (cf. Allen 2000).

Inertia can be neglected when it is small, not only relative to the geostrophic balance but also to friction. This is true when $L_{y}^{-1} V T \ll 1$ for a flow whose speed scales as $V$, varies over an alongshore length scale $L_{y}$, and is slowed with a frictional timescale $T$. The results below are self-consistent with this limit. It will be found below that the length scale of alongshore variation of alongshore velocity is of the order of hundreds of kilometers and reasonable values for the other parameters are $V=0.2 \mathrm{~m} \mathrm{~s}^{-1}$ and 2-4 days for $T$ (Dever 1997; Lee et al. 1989; Lentz et al. 1999), so the ratio of inertial to frictional forces is $O\left(10^{-1}\right)$. On timescales greater than $T$, the flow can be treated as quasi-steady (Dever 1997).

The steady, linear, homogeneous equations of motion, valid in the limits described above, are

$$
\begin{aligned}
-f V & =-g H \eta_{x}+\frac{\tau_{\text {top }}^{x}}{\rho_{0}}-\frac{\tau_{\text {bot }}^{x}}{\rho_{0}} \\
f U & =-g H \eta_{y}+\frac{\tau_{\text {top }}^{y}}{\rho_{0}}-\frac{\tau_{\text {bot }}^{y}}{\rho_{0}} \\
U_{x}+V_{y} & =0,
\end{aligned}
$$

where $U$ and $V$ are the depth integrated cross- and alongshore velocity. To close these equations, the bottom stress $\tau_{\text {bot }}$ must be related to the depth integrated flows $U$ and $V$. It is convenient, and realistic in the presence of strong tidal and surface wave driven flows, to assume a linear drag law:

$$
\begin{aligned}
\tau_{\text {bot }} & =\rho_{0} r \mathbf{u}_{\text {bot }} \\
r & \approx 2 C_{d}\left\langle\mathbf{u}_{\text {bot }}\right\rangle,
\end{aligned}
$$

where $\left\langle\mathbf{u}_{\text {bot }}\right\rangle$ is the root-mean-square of all bottom velocities, not just the low-frequency ones of interest here (Lentz et al. 1999; Wright and Thompson 1983). The near-bottom velocity must then be related to the depthintegrated velocity and here is set to the depth-integrated velocity divided by the water depth:

$$
\boldsymbol{\tau}_{\text {bot }}=\rho_{0} r \frac{\mathbf{U}}{H} \text {. }
$$

This can be shown to be reasonable for the surface pressure gradient forced flows in weakly stratified oceans (Brink and Allen 1978). It is more problematic for surface Ekman flows, which are trapped to the surface by rotation and thus should not feel bottom drag. The error in the surface Ekman transport scales as 
$r^{2} H^{-2} f^{-2}$, so this analysis will be confined to where that parameter is small.

The transport streamfunction $U=-\Psi_{y}$ and $V=\Psi_{x}$ can be used to rewrite (4) as a potential vorticity equation:

$$
0=\underbrace{J\left(\Psi, \frac{f}{H}\right)}_{\text {Advection of } f / H}+\underbrace{\nabla\left(\frac{r}{H^{2}} \nabla \Psi\right)}_{\text {Friction }}-\underbrace{\nabla \times\left(\frac{\boldsymbol{\tau}_{\text {top }}}{\rho_{0} H}\right)}_{\text {Wind torque }} .
$$

There are only three terms in the linear, steady and homogeneous potential vorticity equation (7) - the advection of planetary potential vorticity, the dissipation of relative vorticity by bottom friction and other frictional effects, and the input of potential vorticity by a curl in the wind stress.

The latitudinal variation in $f$ will be neglected below because for the alongshore length scales described below the cross-shelf topographic gradient of potential vorticity is much more important than the planetary gradient of potential vorticity.

\section{Changing shelf width and wind-driven flows}

Equation (7) can be solved numerically (see appendix), and a solution is shown in Fig. 1 for a uniform upwelling wind along a northern hemisphere shelf whose width halves from $30 \mathrm{~km}$ in the south to $15 \mathrm{~km}$ to the north and for a uniform downwelling wind along a shelf whose width doubles to the north. The shelf slopes linearly from $10 \mathrm{~m}$ at the coast to $110 \mathrm{~m}$ at the shelf break, then deepens to $3000 \mathrm{~m}$ over the next 40 $\mathrm{km}$ offshore. The coastal boundary condition is no flow through the coast, while the other boundary conditions, detailed in the appendix, are chosen so the solution is nearly identical to the solution for an $f$-plane ocean that extends infinitely and without change to the north, south, and west. In all model runs presented below, $f=10^{-4}$ $\mathrm{s}^{-1}$ and $r=5 \times 10^{-4} \mathrm{~m} \mathrm{~s}^{-1}$. The cross-shelf grid spacing is $0.65 \mathrm{~km}$, the alongshelf grid spacing is $1 \mathrm{~km}$, and the problem is solved on a 385 by 385 grid (only part of which is shown in the figures). The solution changes by less than $1 \%$ when the resolution is doubled, and by less than $10 \%$ when it is halved.

The depth averaged currents in Fig. 1a follow the isobaths where the shelf changes width - thus the alongshelf flow is nearly twice as fast in the narrow region near the change in shelf width. Figure $1 \mathrm{~b}$ shows the strength of the alongshore flow, scaled by the strength it would have if there were no variation in the shelf width [from (2)]. It is apparent that the flow immediately to the south of the change in shelf width is not affected by the change in shelf width, and all adjustment to the change in shelf width occurs to the north of the change in both figures. The flow adjusts first near the coast, and the adjustment moves progressively offshore farther to the north. Figure 1c shows the net cross-shelf transport at the midpoint of the shelf. Consistent with the first two panels, there is no net cross-shelf transport south of the change in shelf width-the flow is two-dimensional and the surface Ekman flow is balanced by a bottom Ekman flow. North of the change in shelf width, there is a net onshore transport of water, in both figures, because in both the shelf widens in the direction of the alongshore flow.

This raises four questions: Why does the change in shelf width only affect the flow to the north of the change? Why does the adjustment to the new shelf width occur first near the coast? How far to the north of the change in shelf width is it necessary to go before the flow is not affected by the change? And where does the additional flow enter the shelf, in the bottom boundary layer, geostrophic interior, or surface Ekman layer?

To answer these questions, it is useful to write the vorticity equation (7) in a coordinate system aligned to the isobaths. This coordinate system is illustrated in Fig. 2 . The coordinate $n$ is normal to isobaths, and takes the place of $x$ when isobaths parallel the coast, and $p$ is parallel to an isobath and takes the place of $y$ when isobaths parallel the coast. At any point the coordinate system $(\hat{n}, \hat{p})$ can be chosen so it is only a rotation from $(\hat{x}, \hat{y})$. Equation (7) is then locally

$$
\begin{aligned}
\frac{\partial \psi}{\partial p} \frac{\partial}{\partial n}\left(\frac{f}{H}\right)= & \frac{\partial}{\partial n}\left(\frac{r}{H^{2}} \frac{\partial \psi}{\partial n}\right)+\frac{1}{R}\left(\frac{r}{H^{2}} \frac{\partial \psi}{\partial n}\right) \\
& +\frac{\partial}{\partial p}\left(\frac{r}{H^{2}} \frac{\partial \psi}{\partial p}\right)-\nabla \times\left(\frac{\boldsymbol{\tau}_{\text {top }}}{\rho_{0} H}\right),
\end{aligned}
$$

where $R$ is the radius of curvature of the isobath at that point.

Equation (8) can be scaled, and a consistent balance found, if the along-isobath length scale is assumed to be $H f / r$ times the across-isobath length scale. The third term on the right-hand side of (8) is found to scale as $r^{2} H^{-2} f^{-2}$ times the left-hand side and the first term on the right-hand side. Since for typical continental shelves $r^{2} H^{-2} f^{-2}$ is small, the third term on the right-hand side is dropped (for $H=50 \mathrm{~m}, r=5 \times 10^{-4} \mathrm{~m} \mathrm{~s}^{-1}$, and $f=10^{-4} \mathrm{~s}^{-1}, r^{2} H^{-2} f^{-2}$ is $\left.10^{-2}\right)$. This leaves

$$
\begin{aligned}
\frac{\partial \psi}{\partial p}= & {\left[\frac{\partial}{\partial n}\left(\frac{f}{H}\right)\right]^{-1} } \\
& \times\left[\frac{\partial}{\partial n}\left(\frac{r}{H^{2}} \frac{\partial \psi}{\partial n}\right)+\frac{1}{R}\left(\frac{r}{H^{2}} \frac{\partial \psi}{\partial n}\right)-\nabla \times\left(\frac{\boldsymbol{\tau}_{\text {top }}}{\rho_{0} H}\right)\right] .
\end{aligned}
$$

This is a modified version of Csanady's arrested topographic wave equation (with forcing) written locally as an isobath following coordinate system (Csanady, 1978).

Csanady pointed out the similarity of this equation to a heat equation, with the alongshelf direction taking the place of time. It can be solved as an initial value problem by integrating $\psi$ not in time but along an isobath in the direction of long coastal trapped waves (i.e., with greater $f / H$ on the right). Integrating in the opposite direction would lead to spontaneous singularities from 
Upwelling
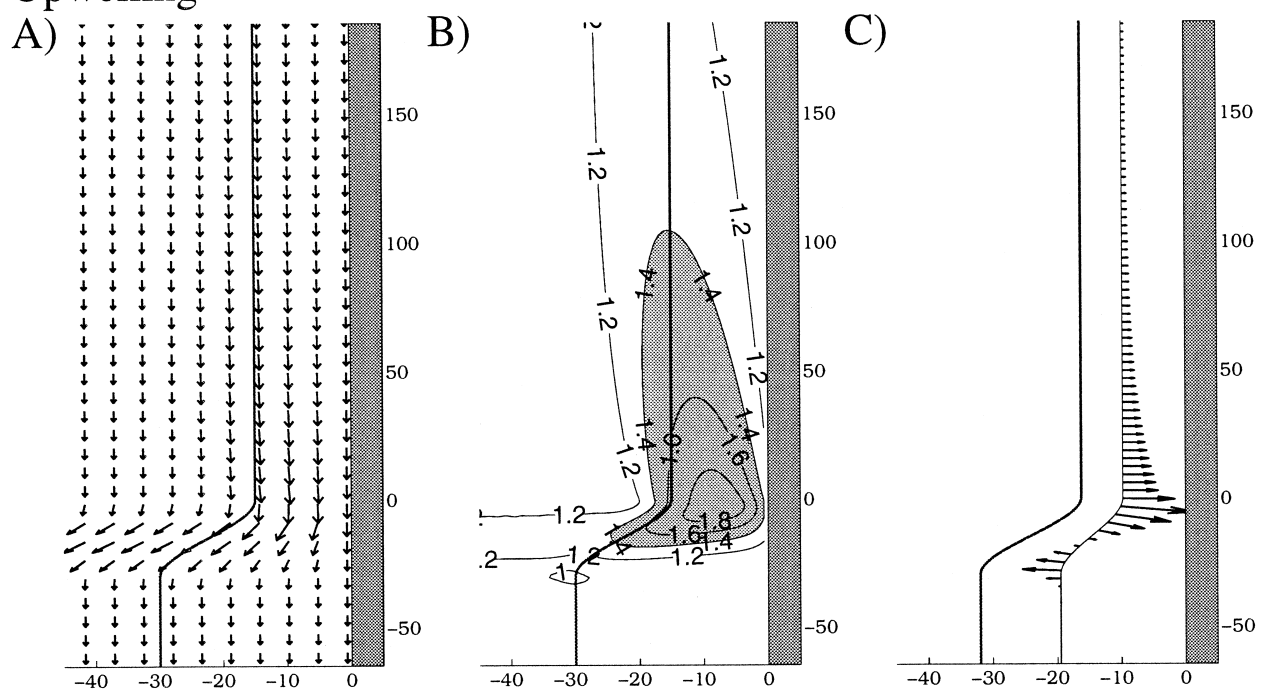

\section{Downwelling}
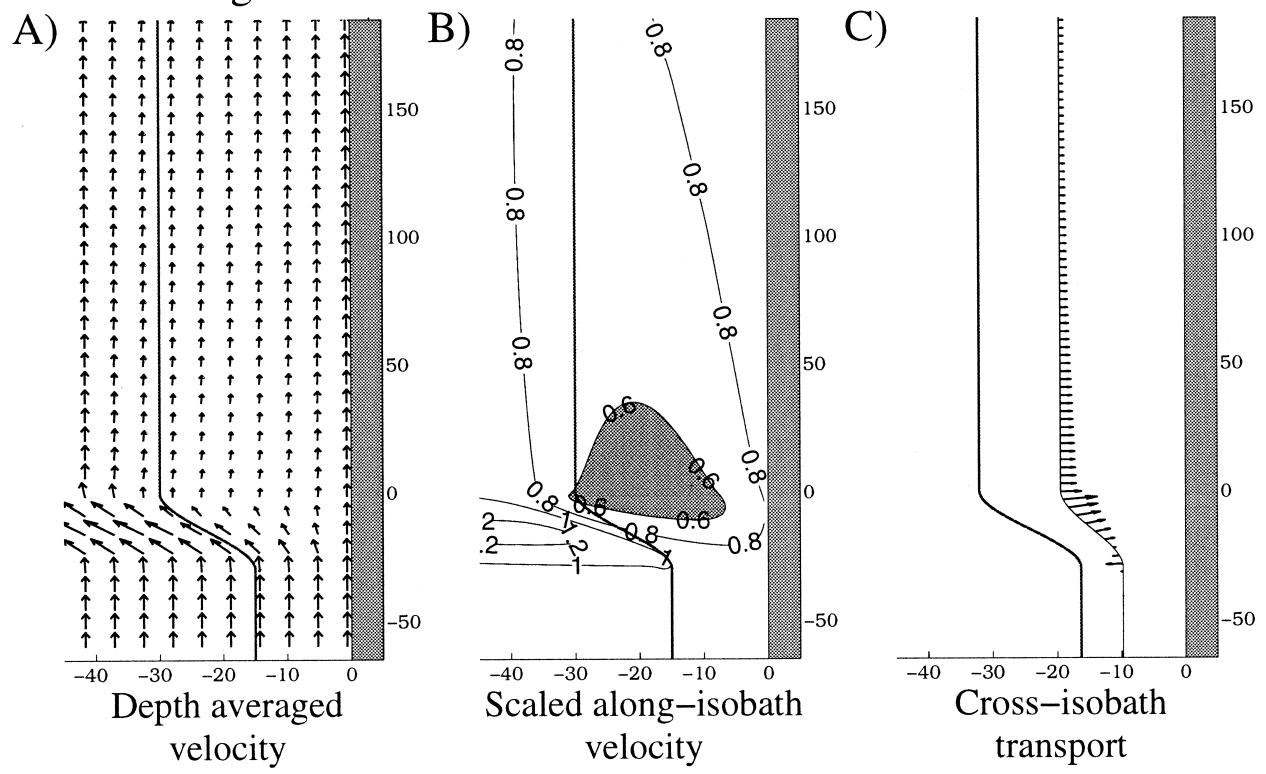

FIG. 1. (top) The flow forced by a uniform upwelling-favorable wind along a Northern Hemisphere shelf that narrows to the north, found by numerically solving (7). (bottom) The flow forced by a uniform downwelling-favorable wind along a Northern Hemisphere shelf that widens to the north. The heavy line marks the 110-m isobath, which is the depth of the shelf break, for all panels: (a) depth-averaged velocity, (b) along-isobath velocity scaled by the along-isobath velocity that would exist in the absence of any change in shelf width, from Eq. (2). Shading indicates where solution deviates from two-dimensional solution by more than $40 \%$. (c) Net cross-isobath transport across the indicated isobath. Along- and cross-shelf axes are not to scale, and arrow lengths in (a) and (c) are not equivalent, for one is a transport, and the other a velocity.

arbitrary initial conditions just as integrating the heat equation backward in time would. Thus any change in the forcing, bathymetry, and so on. only alters the solution to (9) in the direction a long coastal trapped wave will propagate. Thus, we may conclude the following.

Conclusion 1: Any change in shelf width will only affect the flow in the direction of long coastal trapped wave propagation (poleward on a west coast, equatorward on an east coast).

For convenience, the direction in which long coastal trapped waves propagate will be referred to as the "downwave" direction. 


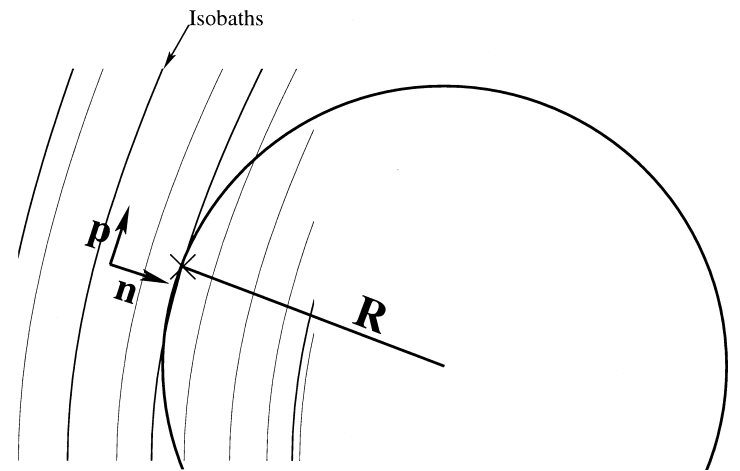

FIG. 2. The new cross- and along-isobath coordinate system. The thin lines are the isobaths. The coordinate $p$ is parallel to isobaths and $n$ is normal; $p$ takes the place of $y$ and $n$ takes the place of $x$ if the isobaths parallel the coast; $R$ is the radius of curvature of the isobaths.

Downwave of the change in shelf width the flow will adjust to the new shelf width. As described in Csanady (1978), the solution will adjust first near the coast, and the influence of the coastal boundary condition will "diffuse" into the interior. The offshore extent of the adjusted region can be estimated by scaling (9) downwave of the region of changing the shelf width. Rewriting (9) by expanding the first term on the right-hand side and dropping the second term (because $R=\infty$ along straight isobaths) leads to an equation, which scales as

$$
\begin{gathered}
\frac{\partial \Psi}{\partial p}=\frac{2 r}{H f} \frac{\partial \Psi}{\partial n}-\frac{r}{f}\left(\frac{\partial H}{\partial n}\right)^{-1} \frac{\partial^{2} \Psi}{\partial n^{2}}+\text { forcing } \\
\frac{\Psi}{L^{y}}=\frac{2 r}{H f} \frac{\Psi}{L^{x}}-\frac{r}{f}\left(\frac{\partial H}{\partial n}\right)^{-1} \frac{\Psi}{L^{x 2}}+\text { forcing }
\end{gathered}
$$

where $L^{y}$ is an alongshore lengthscale and $L^{x}$ is the distance offshore. If the depth is assumed to increase linearly away from the coast, so $H=\alpha x$ and $\partial H / \partial n=$ $-H / L^{x}$, the two terms on the right-hand side are of the same magnitude. All terms of (10) will be of the same magnitude at a distance $L^{x}$ offshore when $L^{y}$ is equal to

$$
L^{\text {fric }}=\frac{1}{2} \frac{H f}{r} L^{x}=-\frac{1}{2} \frac{f}{r} H^{2}\left(\frac{\partial H}{\partial x}\right)^{-1}
$$

[the factor of $1 / 2$ is a scaling factor that arises from a comparison of $L^{\text {fric }}$ to the numerical solutions of (7)]. When much less than $L^{\text {fric }}$ from the change in shelf width ( $L^{y} \ll L^{\text {fric }}$ ), the term on the right-hand side of
(10) is negligible, $\partial \psi / \partial p \approx 0$, and the streamfunction is constant on a line of constant $f / H$. When much farther than $L^{\text {fric }}$ downwave from the change in shelf width, the terms on the right-hand side of (10) dominate, there is a balance between the frictional terms and the forcing, and the flow has equilibrated to the new shelf width. Thus,

Conclusion 2: A distance $L^{x}$ offshore, at an isobath of depth $H, L^{\text {fric }}$ is the distance downwave from the change in shelf width to the place where the flow has adjusted to the new shelf width; $L^{\text {fric }}$ increases offshore.

Less than $L^{\text {fric }}$ from the change in shelf width, $\psi$ is constant on a line of constant $f / H$. Thus, where the shelf narrows, streamlines converge and the flow is faster and, where the shelf widens, the flow is slower. Since the flow upwave of the change in shelf width is unaffected by the change in width, the along-isobath velocity downwave of the change in shelf width will be approximately the ratio of the upwave isobath spacing to the downwave isobath spacing times the alongshore velocity that would exist in the absence of a change in shelf width (2) (cf. Figs. 1 and 3).

If the shelf narrows downwave, there is excess transport on the downwave shelf, relative to the two-dimensional solution. As the solution first adjusts to the new shelf width near the shore, the excess transport moves offshore. This causes an offshore jet to form downwave of the change in shelf width. Farther downwave from the change in shelf width, more of the shelf will have adjusted to the new width and the jet must move farther offshore. The inner edge of the jet is roughly marked by the locus of points where $L^{\text {fric }}$ is equal to the distance from the change in shelf width (Fig. 3). Chapman (1986) has studied this jet in the more general and realistic case where the bottom friction $r$ decreases offshore. The depth-dependent $r$ narrows and elongates the jet, and traps it more strongly to the shelf break. An identical argument can be made for the elongated region of anomalously low flow, an "antijet," downwave of a widening shelf (Fig. 1).

In order to understand how the change in shelf width affects the biology, chemistry, and heat content of the coastal ocean, it is necessary to understand where additional transport caused by the change in shelf width enters the coastal ocean. Is it in the warm, nutrient-poor surface waters, the entire water column, or in the cold, nutrient-rich waters transported by the bottom Ekman layers?

The strength of the cross-isobath surface Ekman, geostrophic, and bottom Ekman transport can be found from (9), as rewritten below:

$$
-\frac{\partial \psi}{\partial p}=\left[\frac{\partial}{\partial n}\left(\frac{f}{H}\right)\right]^{-1}\left[-\frac{r}{H} \frac{\partial}{\partial n}\left(\frac{1}{H} \frac{\partial \psi}{\partial n}\right)+\frac{r}{H^{2}} \frac{\partial H}{\partial n}\left(\frac{1}{H} \frac{\partial \psi}{\partial n}\right)-\frac{1}{R} \frac{r}{H}\left(\frac{1}{H} \frac{\partial \psi}{\partial n}\right)+\nabla \times\left(\frac{\boldsymbol{\tau}_{\text {top }}}{\rho_{0} H}\right)\right]
$$


where $-\partial \psi / \partial p$ is the cross-isobath transport and $H^{-1} \partial \psi l$ $\partial n$ is the along-isobath velocity.

The first term on the right-hand side is the crossisobath transport caused by the frictional removal of the relative vorticity associated with the cross-isobath gradient of along-isobath velocity-that is, Ekman pumping. Where the relative vorticity is positive, positive potential vorticity is removed by friction. Since in this linear model the potential vorticity is $f / H$ and it must become less, $H$ must become greater and there is an offshore cross-isobath transport (for $f>0$ ). The opposite occurs if the flow has negative relative vorticitynegative vorticity is dissipated and there is an onshore cross-isobath transport. Thus cyclonic relative vorticity leads to offshore transport and anticyclonic relative vorticity to onshore transport. This mechanism moves the entire water column across-isobaths-the cross-isobath transport is geostrophic and associated with along-isobath pressure gradients.

The third term on the right-hand side represents the same physical process, but the relative vorticity is associated with flow along curving isobaths, not cross-isobath gradients of the along-isobath velocity. As above, if the flow along isobaths curves cyclonically, there is an offshore transport; if anticyclonically, an onshore transport. The cross-isobath transport is geostrophic, extends through the water column, and is proportional to the inverse of the isobath curvature.

The second term on the right-hand side does not directly involve vorticity dynamics but, instead, describes the bottom Ekman transport. Direct substitution of a uniform along-isobath transport $V_{g}$ into this term produces, in the limit of $r^{2} H^{-2} f^{-2}$ small, a cross-shelf transport of $-r H^{-1} f^{-1} V_{g}$, which is, from (6), $-\rho_{0}^{-1} f^{-1} \tau_{\text {bot }}-$ the bottom Ekman transport. This transport does not depend on the interior relative vorticity and will be confined within an Ekman depth of the bottom.

The fourth term on the right-hand side of (11) forces the surface Ekman transport when there is no curl in the wind stress. Substituting a uniform along-isobath wind into the fourth term on the right-hand side of (11) produces cross-isobath transports equal to $\rho_{0}^{-1} f^{-1} \tau_{\text {top }}^{y}$, the surface Ekman transport, in the limit of $r^{2} H^{-2} f^{-2}$ small. This transport will be trapped within an Ekman depth of the surface.

The relative strength of each term on the right-hand side of (11), and thus the relative strength of the surface Ekman, geostrophic, and bottom Ekman cross-isobath transports, can be estimated near the change in shelf width. Within $L^{\text {fric }}$ of the change of shelf width, the streamlines nearly follow the isobaths, and the alongisobath velocity scales as the ratio of the upwave to downwave shelf width:

$$
\text { along-isobath velocity }=\frac{1}{H} \frac{\partial \psi}{\partial n}=v_{2 D} \frac{1}{\alpha} \frac{\partial H}{\partial n},
$$
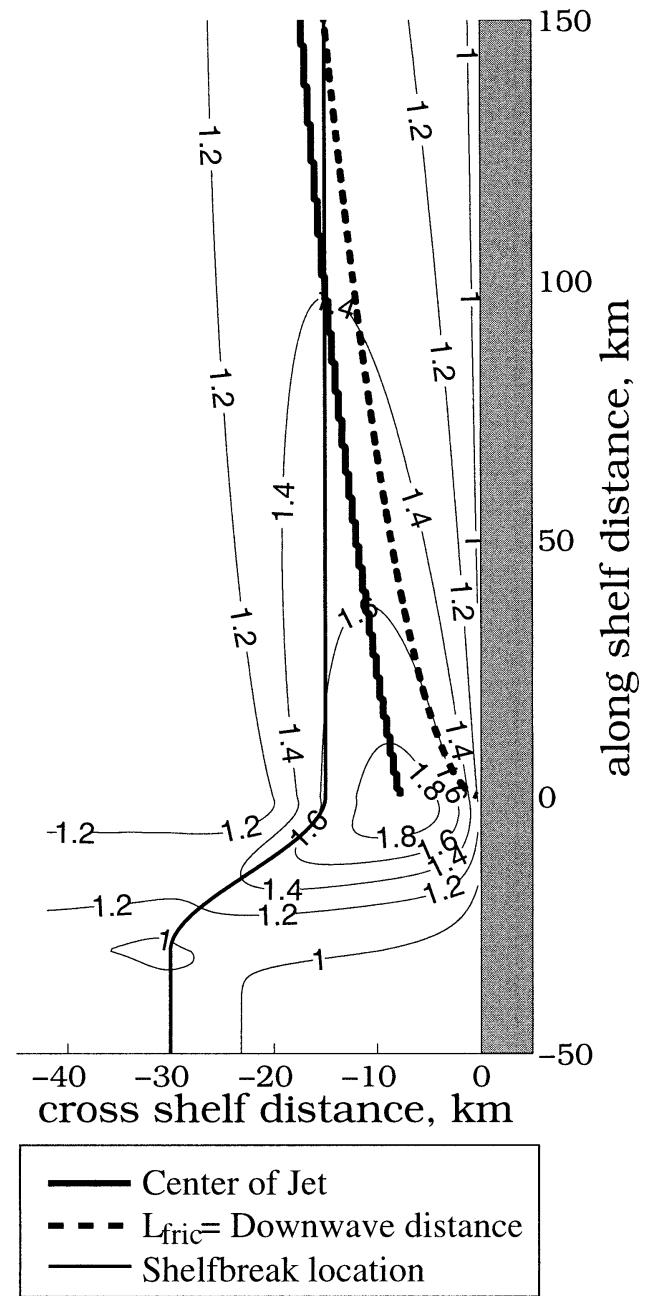

FIG. 3. Along-isobath velocity scaled by the along-isobath velocity that would exist in the absence of any change in shelf width, as in Fig. 1b. Marked on the plot is the cross-shelf position of the point of maximum along-isobath velocity (thick solid line), and the locus where $L^{\text {fric }}$ on an isobath matches the distance downwave from the change in shelf width (dashed line).

where $v_{2 D}$ is the velocity upwave of the change in shelf width [from (2)] and $\alpha(<0)$ is the bottom slope upwave of the change of shelf width on the isobath $H$. In the results described above and shown in Figs. 1-3, the bottom slopes linearly offshore until the shelf break, so $\alpha$ is not a function of depth. In these limits the equation for cross-isobath transport (11) reduces to

$$
\begin{aligned}
-\frac{\partial \psi}{\partial p}= & v_{2 D} H\left(\frac{r}{H f}\right)\left[\frac{H}{\alpha}\left(\frac{\partial H}{\partial n}\right)^{-1} \frac{\partial^{2} H}{\partial n^{2}}-\frac{1}{\alpha} \frac{\partial H}{\partial n}+\frac{H}{\alpha} \frac{1}{R}\right] \\
& +\underset{\approx v_{2 D} H(r / H f)}{\operatorname{surface} \text { Ekman. }} .
\end{aligned}
$$

The first term inside the square brackets of (13) controls the cross-shelf transport driven by the frictional 


\section{Cross-isobath bottom} Ekman transport

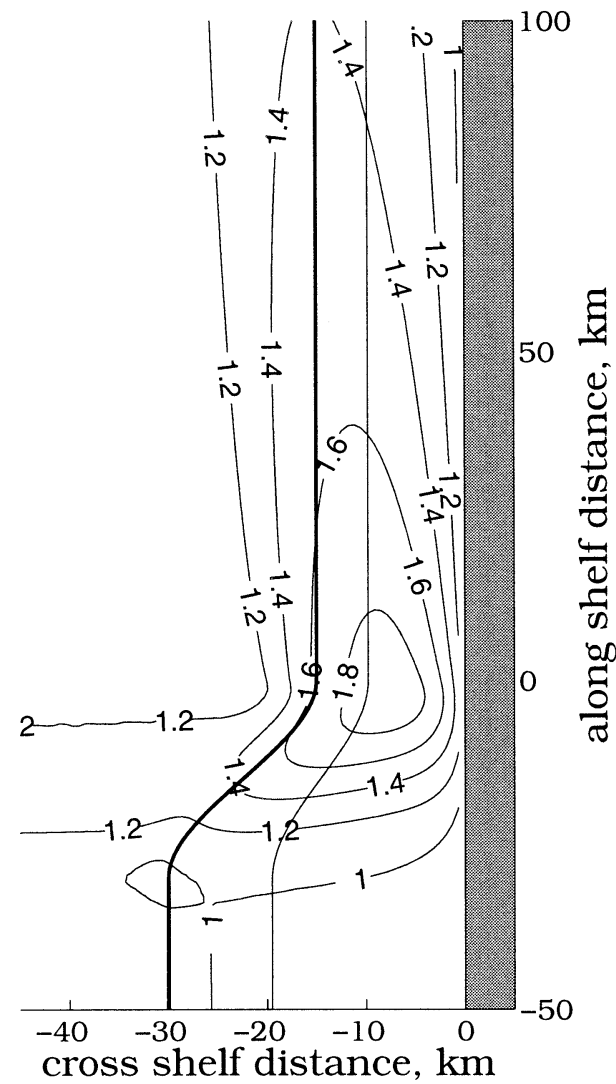

\section{Cross-isobath geostrophic transport}

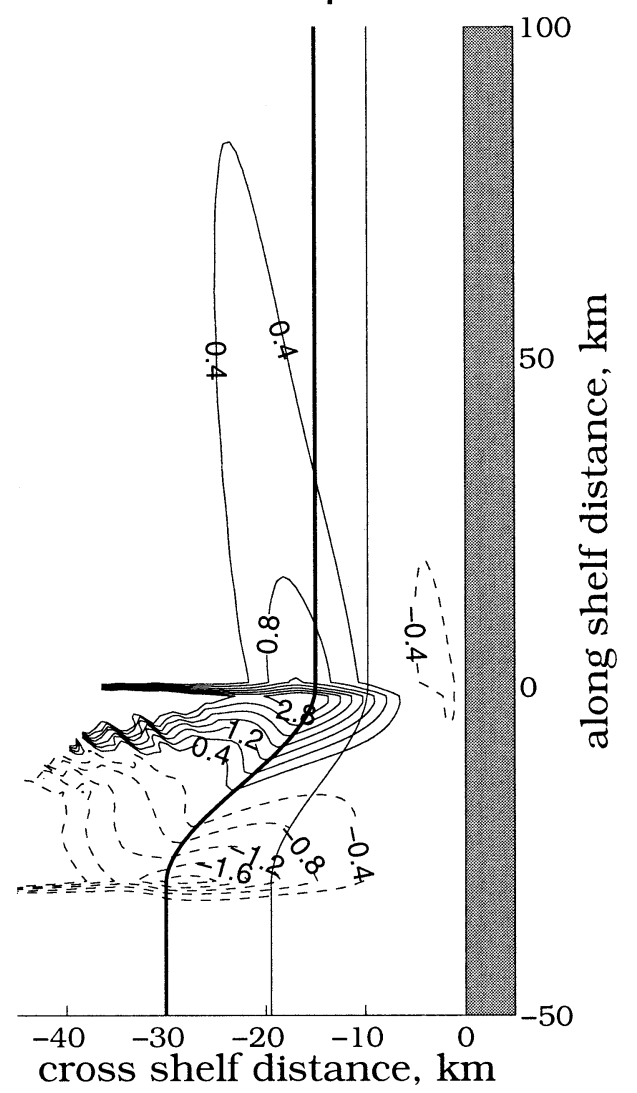

FIG. 4. (left) The bottom Ekman cross-isobath transport, and (right) the geostrophic cross-isobath transport, both normalized by the strength of the surface Ekman transport and both for the upwelling wind case shown in Fig. 1. The heavy offshore line marks the shelf break, the lighter line the 75-m isobath: along- and crossshore axes not to scale. Bottom Ekman transport is calculated from the bottom stress obtained in the numerical solution to (7), and the geostrophic transport from along-isobath pressure gradients is computed from the same solution.

removal of the relative vorticity associated with the cross-isobath gradient of along-isobath flow. The crossisobath transport scales as the surface Ekman transport times the ratio of the shelf width $\left(\alpha^{-1} H\right)$ to the crossshelf length scale of the variation in the alongshelf velocity $\left[(\partial H / \partial n) /\left(\partial^{2} H / \partial n^{2}\right)\right.$ from (12)]. It is small since $\partial^{2} H / \partial n^{2}$ is small where the depth increases linearly offshore to the shelf break, as it does in Figs. 1-3. This flow would be geostrophic and extend through the water column. It is the linear, frictional equivalent to the crossisobath transport described by Janowitz and Pietrafesa (1982).

The second term inside the brackets of (13) controls the bottom Ekman layer cross-isobath transport. It scales as $r H^{-1} f^{-1}$ times the along-isobath velocity and, thus from (12), as the inverse of the ratio of the change in shelf width times the surface Ekman transport. Where the shelf narrows downwave $\left(\alpha^{-1}(\partial H / \partial n)>1\right)$, it becomes greater than the surface Ekman transport; where the shelf widens downwave, it becomes less than the surface Ekman transport. The change in the bottom Ekman transport dominates the change in cross-isobath transport downwave of where the shelf changes width (Figs. 4 and 5). The bottom Ekman transport is trapped to within an Ekman depth of the bottom.

The third term inside the brackets of (13) controls the cross-shelf transport driven by the frictional removal of the relative vorticity associated with flow along curving isobaths. It scales as the surface Ekman transport times the ratio of the topographic length scale $\left(H \alpha^{-1}\right.$, or approximately the distance offshore) to the radius of curvature of the isobaths, $R$. When the shelf width changes by $O(1)$ in a distance comparable to the shelf width, as in Figs. 1-5, the radius of curvature will be approximately the shelf width where the shelf changes width, and will be of one sign when the shelf starts changing width and the other sign when the isobaths straighten out. This curvature drives a cross-shelf transport comparable to the surface Ekman transport in the region of changing shelf width, onshore where the flow curves 

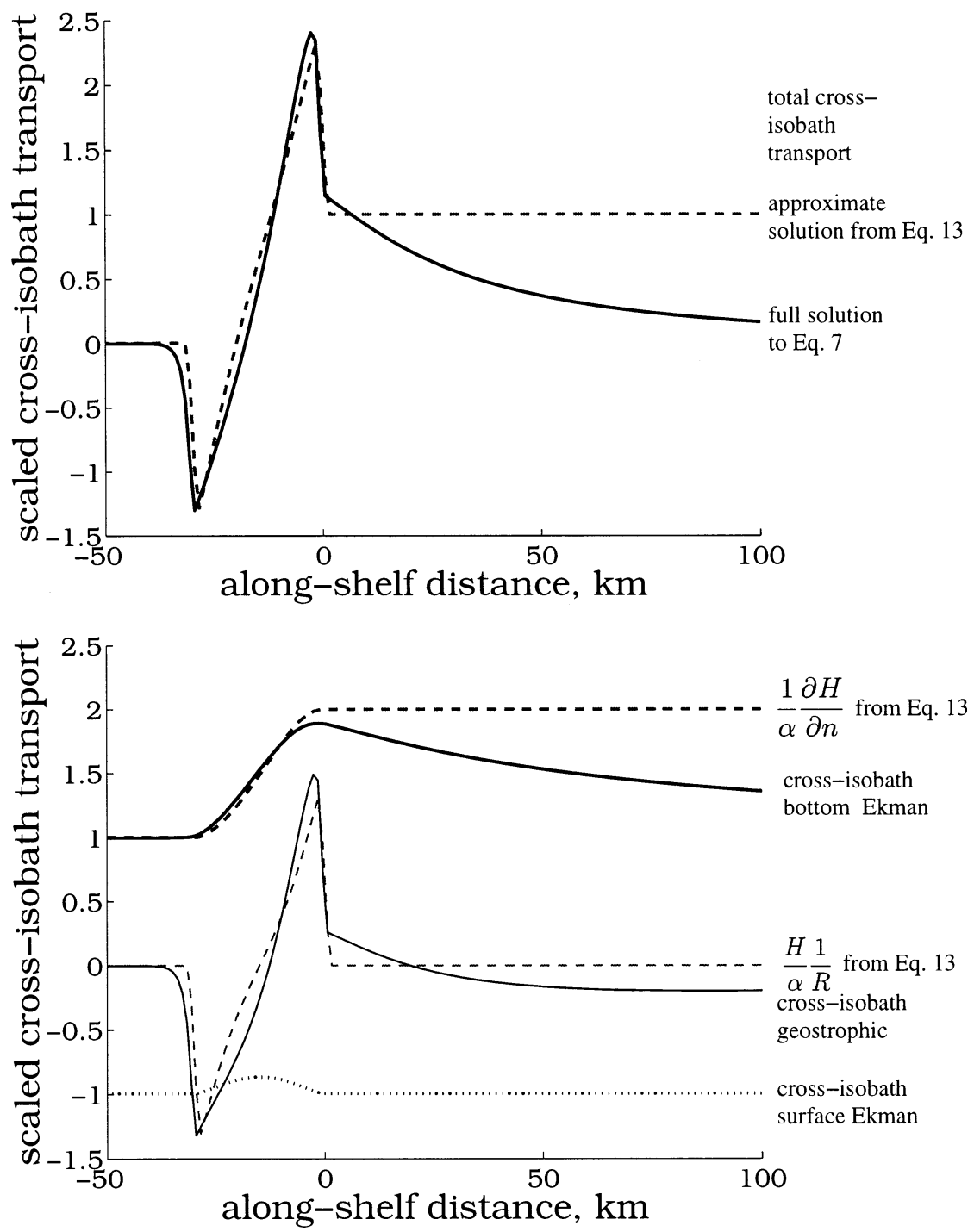

FIG. 5. (top) Total cross-isobath transport from numerical solution to (7) and from estimate in (13), both scaled by surface Ekman transport. (bottom) Cross-isobath surface Ekman, bottom Ekman, and geostrophic transports from numerical solution to (7) and from estimate in (13), also scaled by the surface Ekman transport. Both are calculated along the 75-m isobath marked in Fig. $4 ; L^{\text {fric }}$ is $84 \mathrm{~km}$ on the $75-\mathrm{m}$ isobath. As the flow adjusts to the new shelf width, the cross-shelf transport relaxes back to the two-dimensional solution.

anticyclonically and offshore where it curves cyclonically (Figs. 4 and 5). This cross-isobath transport is geostrophic and will extend throughout the water column. Since the curvature driven flow will tend to be of equal magnitude but opposite sign as the shelf starts to narrow and stops narrowing, the net curvature-driven cross-isobath transport in the region of changing shelf width is small. Once the isobaths parallel the coast again, the curvature term is zero.

Thus a change in shelf width changes the cross-isobath transport primarily by changing the strength of the bottom Ekman transport. From this we can understand how the net onshore transport downwave of the two changes in shelf width in Fig. 1 differ in their impli- cations for the biology, heat content, and chemistry of the coastal ocean. In the top panels of Fig. 1, an upwelling wind blows along a coast that narrows in the direction of long coastal trapped wave propagation. The alongshore flow is faster where the shelf narrows. This faster flow enhances the onshore flow in the bottom Ekman layer so that it is stronger than the offshore surface Ekman transport. There is then a net onshore transport of cold, nutrient-laden bottom water onto the shelf (Fig. 6a). Conversely, in the bottom panels of Fig. 1 , a downwelling wind blows along a shelf that widens downwave, and the alongshore flow is slower downwave. This decelerated flow weakens the offshore flow in the bottom Ekman layer so that it is weaker than the 


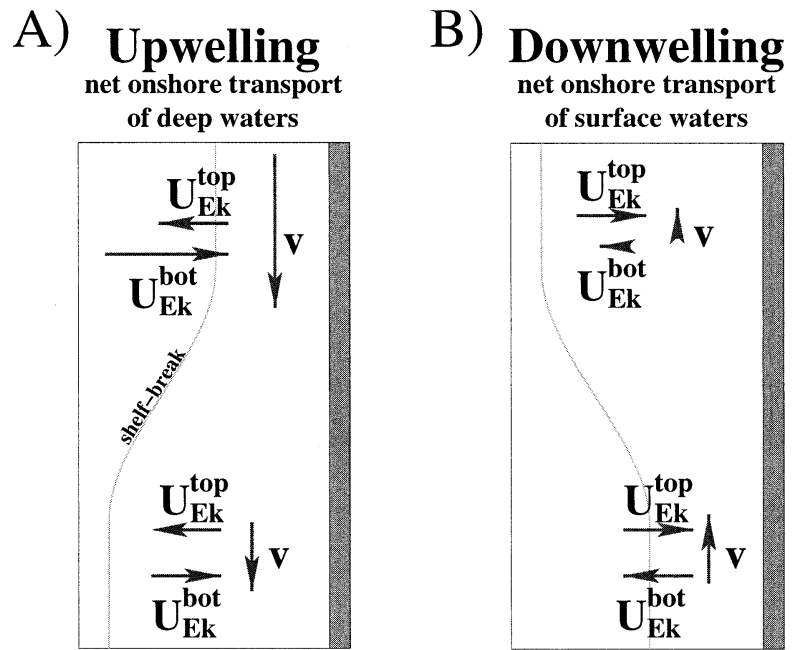

FIG. 6. Additional water is forced onto the shelf when there is upwelling and the shelf narrows downwave, or when there is downwelling and the shelf widens downwave. Both are illustrated above. Only the former forces deep, cold, nutrient-laden waters onto the shelf, because it is only when the alongshore flow is accelerated that the bottom Ekman transport $\left(U_{\mathrm{Ek}}^{\text {bot }}\right.$ ) is enhanced over the surface Ekman transport $\left(U_{\mathrm{Ek}}^{\text {top }}\right)$. Note: alongshore velocity $(v)$ arrows and cross-shelf transport arrows have different scale.

onshore surface Ekman transport. Thus there is also a net transport of water onto the shelf, but it is warm, nutrient poor surface water (Fig. 6b). Thus the final, and perhaps most important, conclusion from this section,

Conclusion 3: The transport of cold, deep, nutrientladen water onto the shelf is enhanced above what it would be along a straight shelf only during upwelling along a shelf that narrows downwave.

Of course, any enhancement of cross-shelf nutrient transport in the bottom boundary layer does not automatically lead to new production on the shelf-some other mechanism must bring the nutrients into the euphotic zone.

\section{Present and possible comparisons to data}

Several of the conclusions above can either be tested against available data or against data that could feasibly be gathered. This will be done or described below.

It is predicted that the flow should adjust to the new shelf width a distance $L^{\text {fric }}$ downwave of a change in shelf width. Because $L^{\text {fric }}$ is less in shallower water, the adjustment occurs first near the coast. After adjustment, the surface and bottom stress are equal and surface and bottom Ekman transports are equal and opposite so that there is no net cross-shelf transport. It might seem practical to test these predictions by measuring where the surface and bottom stress is equal and the alongshore flow agrees with (2).

However, alongshore variation in the wind stress complicates the test for adjustment for, even along a perfectly straight and uniform shelf, the flow at a point is not driven by the winds at that point. Winant (1979), using a variation of (9), and Allen and Denbo (1984), using a coastal trapped wave formalism, show that the flow at a point is governed by the winds upwave of that point. In the steady, linear, and weakly stratified limit described above, the coastal wind $L^{\text {fric }}$ upwave govern the currents at an offshore point.

It is rare to have a good knowledge of the alongshore variation in the winds. It is, however, possible to study the adjustment of the coastal ocean on a shelf that suddenly widens downwave from nearly zero width. Since the downwave flow will be weakened by the ratio of upwave to downwave shelf width, if the upwave shelf has zero width, the upwave influence is infinitely weakened. The alongshore flow will be weak immediately downwave of the widening shelf and will increase nearer to shore and farther downwave. Schwing (1989) examined such a shelf, the Scotian Shelf to the southwest of the Laurentian Channel. The Laurentian Channel truncates the shelf upwave of Nova Scotia. Schwing computed the expected sea surface pressure response along Nova Scotia with a version of (9) modified to include time variation, and compared it to the observed variation in sea surface pressure. In good agreement with the model in his paper and above, the amplitude of the local forced wave response of the ocean to the winds increased both downwave and nearer to the coast. He also found remotely forced sea level pressure variation to be important on the Scotian Shelf. A similar shelf exists near San Francisco, California. At Monterey Bay, the shelf width is nearly zero, and increases to the north. The response of this shelf to an alongshore wind can be examined in a highly idealized model of the shelf north of Monterey in which the coast is straight, the shelf widens from nearly zero width to the north, remains a uniform width near San Francisco, and narrows between Point Reyes and Point Arena. The depth is 10 $\mathrm{m}$ at the coast and $150 \mathrm{~m}$ at the shelf break. Offshore of the shelf break the depth increases to $2150 \mathrm{~m}$ within $100 \mathrm{~km} .{ }^{1}$ Figure 7 shows the transfer function between the wind and the along-isobath velocity, normalized by the value it would have along a shelf of uniform width. There is in the solution a shadow zone offshore of the isobath $L^{\text {fric }}$ downwave of the initial widening of the shelf. These areas are weakly forced by the wind. Observations should show that the transfer function between winds and currents decreases markedly offshore between the coast and shelf break in the region 20 to $200 \mathrm{~km}$ north of Monterey. The currents in the shadow zone should be driven mainly by baroclinic effects and windstress curl. Once the shelf begins to narrow near Point Reyes, the alongshore currents increase.

It is also predicted above that the onshelf transport of cold, nutrient-rich water will be enhanced where there

\footnotetext{
${ }^{1}$ The shelfbreak slope is reduced for numerical convenience. It has little effect on the solution.
} 


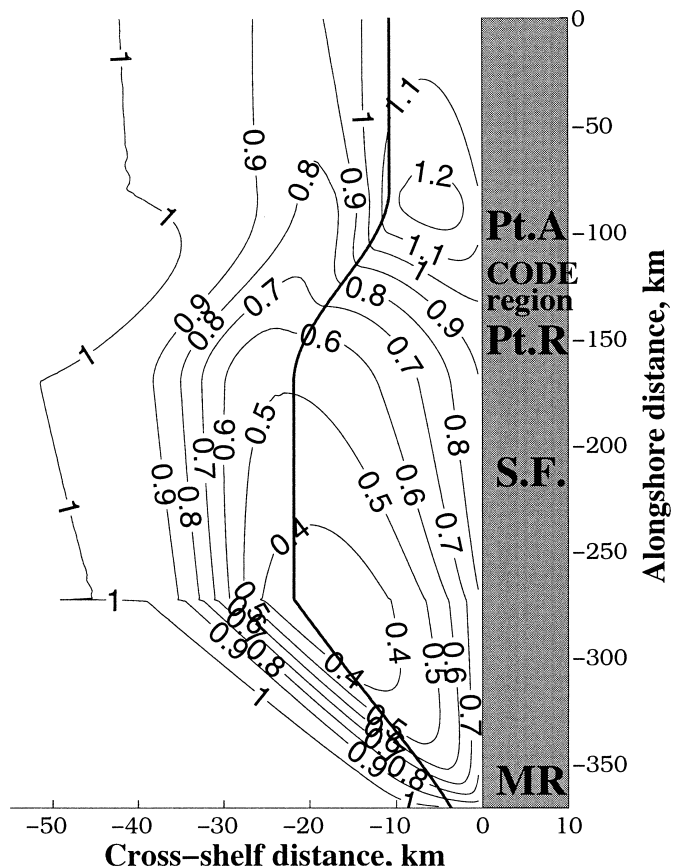

FIG. 7. An idealized model of the region north of Monterey Bay and south of Cape Mendocino. The contours are of the along-isobath velocity, normalized by the velocity along a shelf whose width is constant. The thick black line marks the shelf break: Monterey (MR), San Francisco (S.F.), Point Reyes (Pt.R), and Point Arena, (Pt.A), respectively. The map is not to scale: cross-shelf distance is exaggerated relative to alongshelf distance.

is upwelling along a coast that narrows in the direction of long coastal trapped wave propagation. The alongshelf transport will be significantly altered, and thus a significant amount of water added to the shelf, over a distance of $L^{\text {fric }}$, defined with the depth of the shelf break. For a shelf break depth of $150 \mathrm{~m}$, bottom friction of $r=5 \times 10^{-4} \mathrm{~m} \mathrm{~s}^{-1}$, and shelf widths from 5 to 30 $\mathrm{km}, L^{\text {fric }}$ will range from 75 to $450 \mathrm{~km}$. In Fig. 8, regions where the shelf from Baja California to Cape Mendocino narrows downwave for a hundred or more kilometers are marked.

From Point Eugenia to La Jolla, San Luis Obispo to Monterey, and the CODE region to Cape Mendocino, the shelf narrows to the north and thus downwave. Measurements in these regions, taken when there are upwelling winds, should confirm that there is more onshore transport in the bottom Ekman layer than offshore transport in the surface Ekman layer. These observations are hard to make-small pointing errors in the current meters can fold the strong along-isobath currents into the much weaker cross-isobath currents. It will likely be more robust to measure the alongshelf transport at either end of these regions. There ought to be $O(1)$ changes in alongshore transport, with more transport at the southern, upwave ends of the shelves. The southern ends of these regions should also have lower mean heat contents and higher mean nutrient concentration, while heat

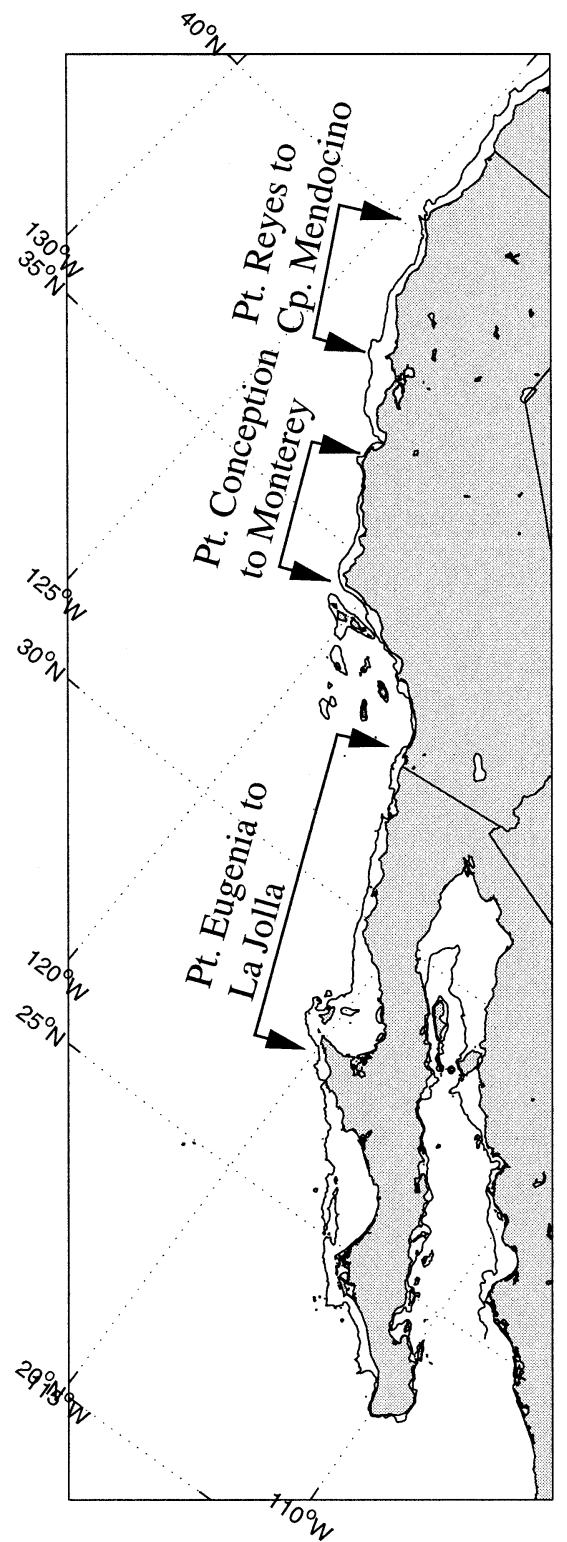

FIG. 8. The coast of North America from Mexico to the northern California border. The 200-m isobath is included, and regions where the shelf narrows downwave for more than a $100 \mathrm{~km}$ are labeled.

and nutrient budgets should require fluxes of heat off the shelf, and nutrients onto the shelf, to close.

\section{Conclusions and discussion}

The main conclusions of this work are fourfold. First, in the weakly stratified, linear, and frictional limits described in section 2, the effects of any change in the shelf width are confined to the region of changing shelf width and downwave of the change. Thus on a western coast, a change in shelf width only affects the flow poleward of the change, and on east coasts equatorward.

Second, the effects of the change in shelf width are 
felt for a distance $L^{\text {fric }}$ downwave of the change in shelf width; $L^{\text {fric }}$ increases with depth. For a shelf typical of the western coast of North America, the bottom slope is about $5 \times 10^{-3}, f=10^{-4} \mathrm{~s}^{-1}$, and $r=5 \times 10^{-4} \mathrm{~m}$ $\mathrm{s}^{-1}$, so $L^{\text {fric }}$ is $8 \mathrm{~km}$ on the $20-\mathrm{m}, 50 \mathrm{~km}$ on the $50-\mathrm{m}$, and $200 \mathrm{~km}$ on the $100-\mathrm{m}$ isobath. Thus shallow waters adjust to new shelf widths most rapidly, returning to a balance between surface and bottom Ekman transports, while at greater depths the effect of a change in shelf width is felt farther downwave. Also $L^{\text {fric }}$ increases as shelf width increases; thus, on wider shelves, the effect of a change in shelf width is felt farther downwave.

Third, the transport between an isobath and the coast is conserved over distances much less than $L^{\text {fric }}$. This and the first result imply that, where the shelf narrows downwave, the wind-driven flow is made stronger than it would be otherwise and, where the shelf widens downwave, the flow is made weaker. This and the second result imply that a jet, where the shelf narrows downwave, or antijet, where it widens, will be formed offshore and downwave of the change in shelf width. The inshore boundary of the jet or antijet is $L^{\text {fric }}$ downwave from the change in shelf width. Chapman (1986) has studied similar jets and found that they are concentrated near the shelf break and elongated when more realistic bottom friction schemes, in which $r$ decreases offshore, are used. This is because smaller bottom friction causes larger $L^{\text {fric }}$ offshore.

The fourth major conclusion is that there will be enhanced onshelf transport of deep waters, primarily in the bottom boundary layer where the shelf narrows downwave, but only during upwelling. Thus certain places on the shelf will be locations of enhanced crossshelf transport of cold, nutrient-laden water, setting the stage for enhanced primary productivity that will occur when these waters are brought into the euphotic zone.

These four conclusions can alter theoretical and numerical models of the coastal ocean. Many analyses of data assume a simple, almost two-dimensional, picture of the coastal ocean, in which surface and bottom Ekman fluxes balance, only to find that this does not explain the observations well, especially on the mid and outer shelves. But as described above, the along-isobath flow, and thus the cross-isobath bottom Ekman transport, are forced by the winds and modified by changes in shelf width $L^{\text {fric }}$ downwave. Near the coast, $L^{\text {fric }}$ is small, so the flow is nearly locally forced. Farther offshore, this is not true. On an east coast midshelf, where the depth is $75 \mathrm{~m}, r$ and $f$ are as above, and the bottom slope $10^{-3}, L^{\text {fric }}$ is $560 \mathrm{~km}$, a distance over which shelf width, bottom slope, and coastal wind stress will usually have changed significantly. Thus the magnitude of the surface and bottom Ekman transports at a point will often be unequal.

Similar issues are important to numerical modelers of continental shelf circulation: $L^{\text {fric }}$, especially on wide shelves or near the shelf break, will often be comparable to or larger than the model domain. The outer and mid shelves of these models will be controlled by winds and bathymetry outside of the model domain, and thus by whatever open boundary condition the modeler sets on the upwave boundary. It will often be impractical, and always wasteful, to remove this problem by extending the model domain $L^{\text {fric }}$ upwave, where $L^{\text {fric }}$ is defined at the greatest depth of interest. Since the dynamics described above are barotropic, it would often be more practical to obtain the upwave surface pressure gradient boundary condition from a much more economical shallow-water model whose domain extends $L^{\text {fric }}$ upwave of the region of interest. The upwave boundary of the shallow water model could be forced by a coastal trapped wave model to capture even more remotely forced dynamics (Battisti and Hickey 1984).

Further extension of this work will most likely describe the influence of stratification on the results described above. Cross-isobath advection of density in the bottom boundary layer can, at long time, cause bottom Ekman transport to shut down or be reduced (Trowbridge and Lentz 1991). This will eliminate or reduce the dominant adjustment mechanism to changed shelf width, cross-shelf bottom Ekman transport, and some other adjustment mechanism must become dominant. What this might be is, at present, unclear.

Acknowledgments. I wish to thank Peter Franks for allowing me to pursue this idea, even as it drifted further away from the biophysical modeling I was to be doing. Ken Brink kindly reviewed the manuscript, and his suggestions, along with those of two anonymous reviewers, improved it greatly. This work was funded through Grants NA76GP0176 and NA960P0366 to Peter J. S. Franks from NOAA for North Atlantic GLOBEC program.

\section{APPENDIX}

\section{The Numerical Solution of (7)}

The solution to the vorticity equation (7) described above is meant to be identical to the solution on a semiinfinite $f$-plane coastal ocean, but must be computed on a finite numerical domain. A coastal boundary condition and three open boundary conditions, on the upwave, downwave, and offshore boundaries, must thus be specified. The coastal boundary condition is that there be no flow through the coast, so $\Psi=0$ at $x=0$.

The most important of the open boundary conditions is that on the upwave cross-shelf boundary, for it is the "initial condition" that the heat equation like (9) propagates through the domain. Since the domain upwave of the numerical domain is assumed to be without alongshore variation, a natural choice for boundary conditions is $\Psi_{y}=0$ at the upwave boundary.

The downwave boundary is harder to specify but, if the domain extends farther than $L^{\text {fric }}$ downwave, the flow will have adjusted to the new shelf width and ceased to 
vary alongshore, so $\Psi_{y}=0$ at the downwave boundary would be appropriate. However, nearly any other boundary condition will work as well, for any boundary condition induced error is trapped near the boundary by the downwave propagation of information. For example, if there is a wall $(\Psi=0)$ at the downwave boundary, any error is contained within a frictional boundary layer near the wall. This boundary layer is dynamically equivalent to the Stommel (1948) solution for the width of the Gulf Stream and has a width $\sqrt{r \beta^{-1}}$, where $\beta$ is the quasigeostrophic topographic potential vorticity gradient $\beta$. This width is only several hundred meters for the problem described above. Outside of this boundary layer, the flow is unaffected by the boundary condition. This has been verified numerically.

The offshore boundary condition should allow flow into the domain to adjust for the change in transport along the shelf, and thus $\Psi$ ought to be allowed to vary along the boundary. If there is no wind at the boundary, there should be no alongshore flow (at least where the shelf width is uniform) at the boundary. Thus well offshore of the region of interest, the wind is allowed to decay to zero, and $\Psi_{x}$ is set to zero at the offshore boundary. However, the solution on the shelf is nearly unaffected by this boundary condition because of the strong potential vorticity gradients on the shelf slope. This was verified by varying the offshore extent of the model and altering the offshore boundary condition.

The geometry of the coastal ocean shown in Figs. 15 was chosen so that the gradient of water depth was everywhere continuous. The shelf slopes linearly from depth $h_{0}$ to depth $h_{0}+h_{\mathrm{sb}}$ over a distance $x_{\mathrm{sh}}$. Over the shelf slope, the depth smoothly but rapidly increases to a depth $h_{\mathrm{ab}}$ over a distance $x_{\mathrm{sh}}$, and offshore of $-\left(x_{\mathrm{sh}}+\right.$ $x_{\mathrm{sl}}$ ) the bottom is flat at a depth of $h_{\mathrm{ab}}$. The width of the shelf changes smoothly from $x_{\mathrm{sh}}=x_{\text {upwave }}$ to $x_{\mathrm{sh}}=x_{\text {downwave }}$ over a distance $\Delta y$ centered around $y=0$. For the results shown in Figs. 1-5, $\Delta y=25 \mathrm{~km}$ and the other parameters are as described in section 3 .

Equation (7) is then solved with the mud2 elliptic equation solver described in Adams (1989). This is computationally inefficient for it is solving a nearly hyperbolic system with an elliptic equation solver, but it does work.

\section{REFERENCES}

Adams, J., 1989: MUDPACK: Multigrid Fortran software for the efficient solution of linear elliptic partial differential equations. Appl. Math. Comput., 34, 113-146.

Allen, J. S., and D. W. Denbo, 1984: Statistical characteristics of the large-scale response of coastal sea level to atmospheric forcing. J. Phys. Oceanogr., 14, 1079-1094.

Allen, S. E., 2000: On subinertial flow in submarine canyons: Effect of geometry. J. Geophys. Res., 105 (C1), 1285-1297.

Austin, J. A., 1998: Wind-driven circulation on a shallow, stratified shelf. Ph.D. thesis, Massachusetts Institute of Technology and Woods Hole Oceanographic Institution Joint Program, 246 pp.

Battisti, D. S., and B. M. Hickey, 1984: Application of remote windforced coastal trapped wave theory to the Oregon and Washington coasts. J. Phys. Oceanogr., 14, 887-903.

Brink, K. H., and J. S. Allen, 1978: On the effect of bottom friction on barotropic motion over the continental shelf. J. Phys. Oceanogr., 8, 919-922.

Chapman, D. C., 1986: A simple model of the formation and maintenance of the shelf/slope front in the Middle Atlantic Bight. $J$. Phys. Oceanogr., 16, 1273-1279.

Csanady, G. T., 1978: The arrested topographic wave. J. Phys. Oceanogr., 8, 47-62.

Dever, E. P., 1997: Wind-forced cross-shelf circulation on the northern California shelf. J. Phys. Oceanogr., 27, 1566-1579.

Garrett, C., P. MacCready, and P. Rhines, 1993: Boundary mixing and arrested Ekman layers: Rotating stratified flow near a sloping boundary. Annu. Rev. Fluid Mech., 25, 291-323.

Hogg, N., 1980: Effects of bottom topography on ocean currents. Orographic Effects in Planetary Flows, R. Hide and P. W. White, Eds., GARP Publication Series, Vol. 23, World Meteorological Organization, 167-205.

Janowitz, G. S., and L. J. Pietrafesa, 1982: The effects of alongshore variation in bottom topography on a boundary current-topographically induced upwelling. Cont. Shelf Res., 1, 123-141.

Lee, T. N., E. Williams, J. Wang, and L. Atkinson, 1989: Response of South Carolina continental shelf waters to wind and Gulf Stream forcing during winter 1986. J. Geophys. Res., 94, 10 715-10 754.

Lentz, S. J., 1987: A description of the 1981 and 1982 spring transitions over the northern California shelf. J. Geophys. Res., 92 (C2), 1545-1567.

, 2001: The influence of stratification on the wind-driven crossshelf circulation over the North Carolina shelf. J. Phys. Oceanogr., 31, 2749-2760.

- and C. D. Winant, 1986: Subinertial currents on the southern California shelf. J. Phys. Oceanogr., 16, 1737-1749.

—_, and J. H. Trowbridge, 2001: A dynamical description of fall and winter mean current profiles over the northern California shelf. J. Phys. Oceanogr., 31, 914-931.

_, R. T. Guza, S. Elgar, F. Feddersen, and T. H. C. Herbers, 1999: Momentum balances on the North Carolina inner shelf. J. Geophys. Res., 104, 18 205-18 226.

Schwing, F. B., 1989: Subtidal response of the Scotian Shelf bottom pressure field to meteorological forcing. Atmos.-Ocean, 27, 157180.

Stommel, H., 1948: The westward intensification of wind-driven ocean currents. Trans. Amer. Geophys. Union, 29, 202-206.

Trowbridge, J. H., and S. J. Lentz, 1991: Asymmetric behavior of an oceanic boundary layer above a sloping bottom. J. Phys. Oceanogr., 21, 1171-1185.

- and — 1998: Dynamics of the bottom boundary layer on the northern California shelf. J. Phys. Oceanogr., 28, 2075 2093.

Winant, C. D., 1979: Comments on "The arrested topographic wave." J. Phys. Oceanogr., 9, 1042-1043.

Wright, D. G., and K. R. Thompson, 1983: Time-averaged forms of the nonlinear stress law. J. Phys. Oceanogr., 13, 341-345. 